PREPARED FOR THE U.S. DEPARTMENT OF ENERGY, UNDER CONTRACT DE-AC02-76CH03073

PPPL-3825

PPPL-3825

UC-70

\author{
Gabor Wave Packet Method \\ to Solve Plasma Wave Equations
}

by

A. Pletzer, C.K. Phillips, and D.N. Smithe

June 2003
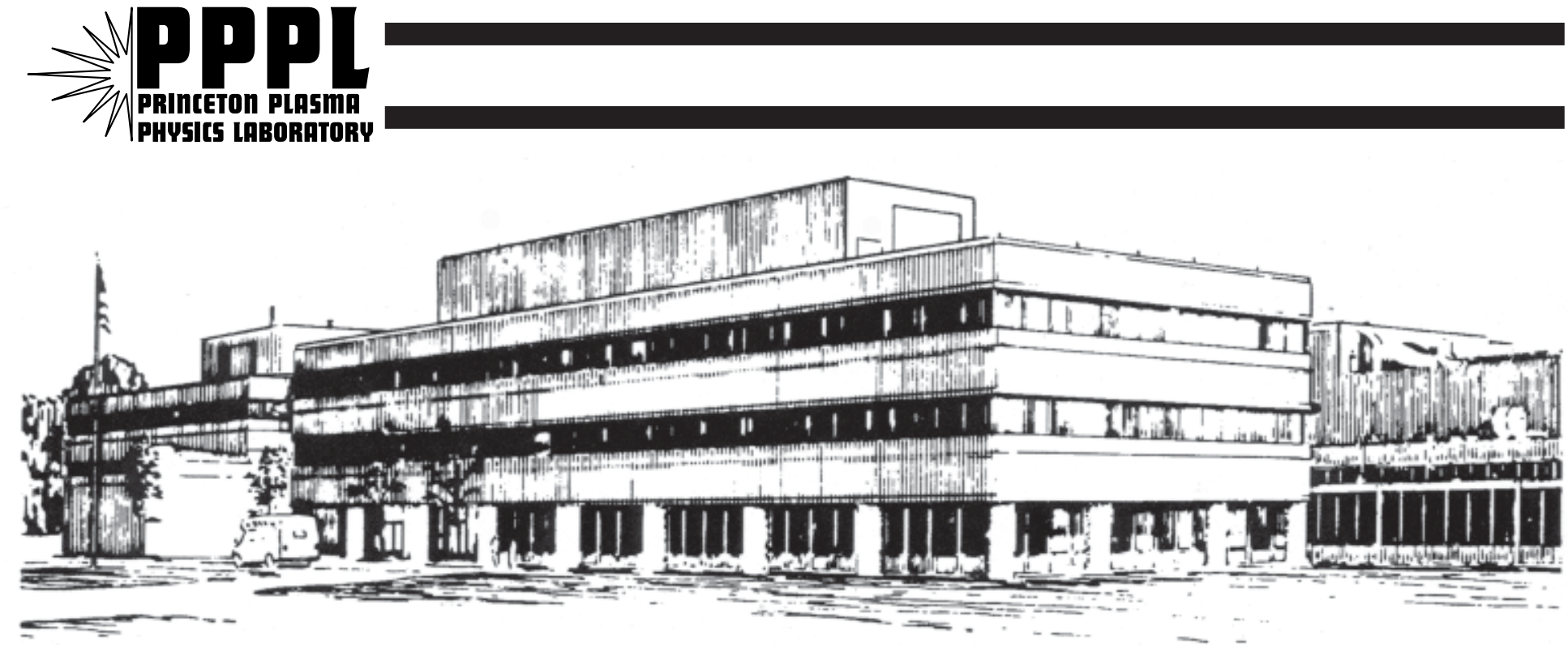

PRINCETON PLASMA PHYSICS LABORATORY PRINCETON UNIVERSITY, PRINCETON, NEW JERSEY 


\section{PPPL Reports Disclaimer}

This report was prepared as an account of work sponsored by an agency of the United States Government. Neither the United States Government nor any agency thereof, nor any of their employees, makes any warranty, express or implied, or assumes any legal liability or responsibility for the accuracy, completeness, or usefulness of any information, apparatus, product, or process disclosed, or represents that its use would not infringe privately owned rights. Reference herein to any specific commercial product, process, or service by trade name, trademark, manufacturer, or otherwise, does not necessarily constitute or imply its endorsement, recommendation, or favoring by the United States Government or any agency thereof. The views and opinions of authors expressed herein do not necessarily state or reflect those of the United States Government or any agency thereof.

\section{Availability}

This report is posted on the U.S. Department of Energy's Princeton Plasma Physics Laboratory Publications and Reports web site in Fiscal Year 2003. The home page for PPPL Reports and Publications is: http://www.pppl.gov/pub_report/

DOE and DOE Contractors can obtain copies of this report from:

U.S. Department of Energy

Office of Scientific and Technical Information

DOE Technical Information Services (DTIS)

P.O. Box 62

Oak Ridge, TN 37831

Telephone: (865) 576-8401

Fax: (865) 576-5728

Email: reports@adonis.osti.gov

This report is available to the general public from:

National Technical Information Service

U.S. Department of Commerce

5285 Port Royal Road

Springfield, VA 22161

Telephone: $1-800-553-6847$ or

(703) $605-6000$

Fax: (703) 321-8547

Internet: http://www.ntis.gov/ordering.htm 


\title{
Gabor wave packet method to solve plasma wave equations
}

\author{
A. Pletzer*, C. K. Phillips* and D. N. Smithe ${ }^{\dagger}$ \\ * Princeton Plasma Physics Lab, Princeton NJ 08543 \\ ${ }^{\dagger}$ Mission Research Corporation
}

\begin{abstract}
A numerical method for solving plasma wave equations arising in the context of mode conversion between the fast magnetosonic and the slow (e.g ion Bernstein) wave is presented. The numerical algorithm relies on the expansion of the solution in Gaussian wave packets known as Gabor functions, which have good resolution properties in both real and Fourier space. The wave packets are ideally suited to capture both the large and small wavelength features that characterize mode conversion problems. The accuracy of the scheme is compared with a standard finite element approach.
\end{abstract}

\section{INTRODUCTION}

The problem of computing RF wave dynamics in fusion plasmas is numerically challenging due to locally fine-scale resonance and short-wavelength mode conversion effects [1]. The conversion of fast magnetosonic into ion Bernstein waves, for instance, requires the resolution of waves with dramatically different wavelengths.

Many codes written (e.g. the Mets code [2]) rely on a Fourier decomposition of the waves, requiring many modes to capture short-wavelength phenomena. Thus, there is a need to explore other more efficient numerical approaches, which provide better local resolution, and can take better advantage of windowing or multiple scale-length aspects of the problem. Due to the constraint that the dielectric tensor is most easily expressed analytically for sinusoidal waves, the extension of Fourier to using wave packets with a Gaussian envelop (Gabor functions) is most natural.

In this article, we explore a novel numerical approach based on expanding the solution in Gabor functions, which combines the advantages of the Fourier and finite element methods. The method, which we refer to as the Gabor element method (GEM), allows for a high degree of flexibility in the specification of boundary conditions. The process of discretization leads to, effectively, a sparse matrix due to the limited support of the Gabor functions. Therefore, GEM shares many similarities with the finite element method (FEM). However, GEM differs from FEM in that a single set of basis functions can be used to solve differential equations, in principle, of arbitrary order.

To validate GEM, we focus on two test problems. First, GEM is applied to solve a second order, Airy-type equation with a linear turning point (cut-off). The solution is then compared to that obtained using linear FEM. Next, a fourth-order, Wasow-type model equation describing the mode coupling between fast and slow waves, with two well separated wavelengths, is solved. 


\section{THE GABOR ELEMENT METHOD}

Our aim is to solve ordinary differential equations of arbitrary order $2 N$ (an even integer),

$$
\sum_{i, j=0}^{N}(-)^{i} \frac{d^{i}}{d x^{i}}\left[f_{i j}(x) \frac{d^{j} y(x)}{d x^{j}}\right]=s(x) ; x \in[0,1],
$$

subject to $N$ boundary conditions at $x=0$ and 1

$$
\frac{d^{i}}{d x^{i}}\left[\sum_{j=0}^{N} f_{N, j}(x) \frac{d^{j} y(x)}{d x^{j}}\right]_{0}^{1}=C_{i}+\sum_{j=0}^{N-1} B_{i j} \frac{d^{j} y(x)}{d x^{j}} ; i=0 \cdots N-1 .
$$

In (1), $f_{i j}$ and $s$ are user supplied functions of the independent variable $x$. Note that conditions (2) are flexible enough to accommodate Dirichlet, Neumann, or Robin boundary conditions by allowing, if required, the $C_{i}$ 's and $B_{i j}$ 's to be infinite.

The Gabor element method is now presented. Following a Galerkin approach, (1) is multiplied by a test function $h(x)$ and integrated over the domain $[0,1]$ to yield

$$
a(h, y)=b(h)
$$

where

$$
\begin{aligned}
a(h, y) \equiv \quad & \int_{0}^{1} d x \sum_{i j} \frac{d^{i} h}{d x^{i}} f_{i j} \frac{d^{j} y}{d x^{j}}+\sum_{i=1}^{N-1} \sum_{\ell=0}^{i}(-)^{i+\ell}\left[\frac{d^{\ell} h}{d x^{\ell}} \frac{d^{i-\ell-1}}{d x^{i-\ell-1}}\left(\sum_{j} f_{i j} \frac{d^{j} y(x)}{d x^{j}}\right)\right]_{0}^{1} \\
& +\sum_{\ell=0}^{N}(-)^{\ell+N}\left[\frac{d^{\ell} h}{d x^{\ell}} \sum_{j} B_{N-\ell-1, j} \frac{d^{j} y}{d x^{j}}\right]_{0}^{1}
\end{aligned}
$$

and

$$
b(h) \equiv \int_{0}^{1} d x h s-\sum_{\ell=0}^{N}(-)^{\ell+N}\left[\frac{d^{\ell} h}{d x^{\ell}} C_{N-\ell-1}\right]_{0}^{1} .
$$

The first term in (4) represents the energy functional while the two subsequent terms arise after integrating by parts $i$ times the term of (1) in [ ]. Next, the solution

$$
y(x)=\sum_{\gamma} g_{\gamma}(x) y_{\gamma} ; g_{\gamma}(x) \equiv \mathrm{e}^{\mathrm{i} 2 \pi u_{j} x} \mathrm{e}^{-\left(x-x_{i}\right)^{2} /\left(2 w_{i}^{2}\right)}
$$

is expanded in Gabor wave packets $g_{\gamma}(x)$ where $\gamma=(i, j)$. Equation (6) is a double expansion in wave-numbers $2 \pi u_{j}, j=-\left(N_{F}-1\right) / 2 \cdots\left(N_{F}-1\right) / 2$ and envelop positions $x_{i}, i=0, \cdots N_{x}$. Upon inserting (6) into (3) and choosing $h(x)=g_{\gamma^{\prime}}$ we then get $N_{x} N_{F}$ linear coupled equations

$$
\sum_{\gamma} A_{\gamma^{\prime}, \gamma} y_{\gamma}=b_{\gamma^{\prime}}
$$

for the unknowns $y_{\gamma}$, where $A_{\gamma^{\prime}, \gamma} \equiv a\left(g_{\gamma^{\prime}}, g_{\gamma}\right)$ and $b_{\gamma^{\prime}} \equiv b\left(g_{\gamma^{\prime}}\right)$. 


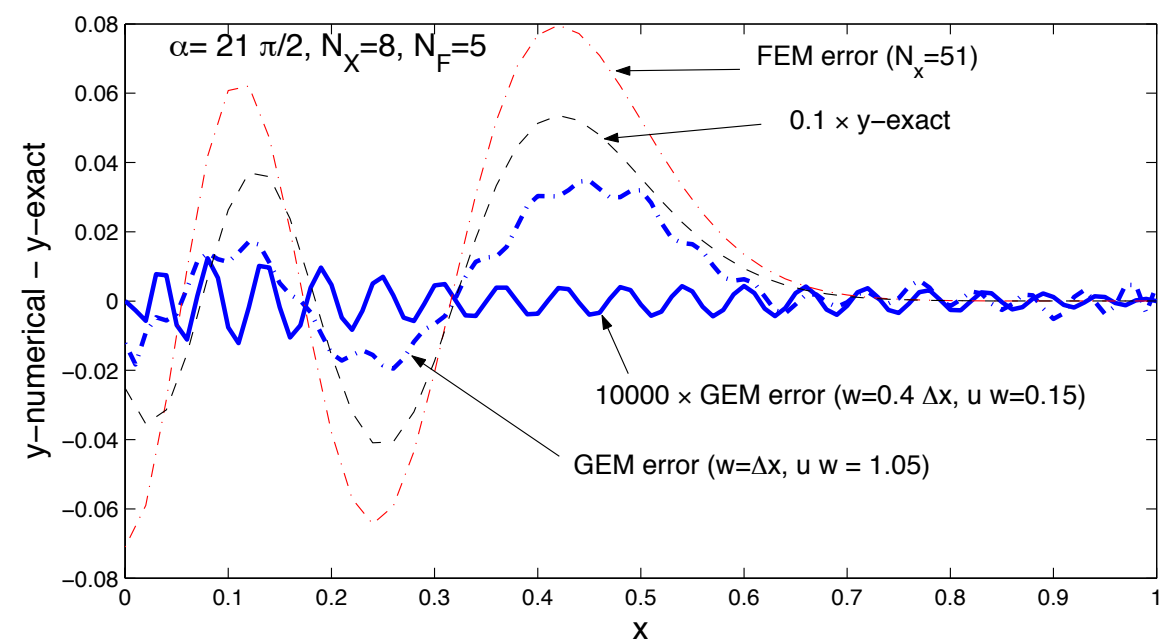

FIGURE 1. Error of the GEM solution for the Airy type equation using two combinations of $u$ and $w$ parameters. Notice the reduction factor of 10000 used to plot the GEM solution obtained using $w=0.4 \Delta x$ and $u w=0.15$. The FEM error obtained using linear hat elements (same number of degrees of freedom) is shown for comparison.

\section{RESULTS}

For simplicity, we will assume in the following that the phase-space lattice is uniform: $x_{i}=i \Delta x$ and $u_{j}=j u$. The accuracy of GEM will depend on the values of the grid spacing $\Delta x$, the fundamental frequency $u$ and the Gaussian (half) width $w$. It can be proved that the Gabors form a frame only under the condition that $u \Delta x<1$ [3]. Moreover, in order for the Gabors to overlap, we must have $2 w \sim \Delta x$.

To determine more precisely the optimal $u$ and $w$ parameters, we solve equation $y^{\prime \prime}+$ $\alpha^{2}(1-2 x) y=0$ whose solution, the Airy function $\operatorname{Ai}\left[(\alpha / 2)^{2 / 3}(2 x-1)\right]$ is a propagating wave for $x<1 / 2$ but evanescent for $x>1 / 2$. Figure 1 shows the pointwise error of the Gabor solution for $\alpha=21 \pi / 2$, using 8 envelops and 5 Fourier modes $(-2 \cdots+2)$. The exact solution (reduced by a factor of 0.1 ) is shown as a dashed line. The GEM error (dash-dotted line) compares favorably with the FEM error obtained using the same number of degrees of freedom. Notice that the FEM error is proportional to the second derivative $y^{\prime \prime}$, as expected for linear hat elements. However, the choice of $w=\Delta x$ and $u w=1.05$ is suboptimal; changing these parameters to $w / \Delta x=0.4$ and $u w=0.15$ suppresses the error by a factor $>10000$. This emphasizes the ability of GEM to capture the solution more accurately than FEM with a small number of degrees of freedom.

To model the coupling of fast to slow waves, we solve the Wasow equation

$$
\left(\frac{d^{2}}{d x^{2}}+k^{2}[1-0.5(x-0.5)]\right)\left(\frac{d^{2}}{d x^{2}}+k^{2}[1-160(x-0.5)]\right) y+\alpha y=0
$$

subject to boundary conditions $y(0)=0, y(1)=1$, and $y^{\prime}(0)=y^{\prime}(1)=0$, with $k^{2}=$ $2 \times 10^{3}$ and $\alpha=8 \times 10^{6}$. To the right of $x=0.506$, the slow wave is evanescent while to the left it is propagating with $\lambda \rightarrow 0.01$. The wavelength of the fast wave ranges 

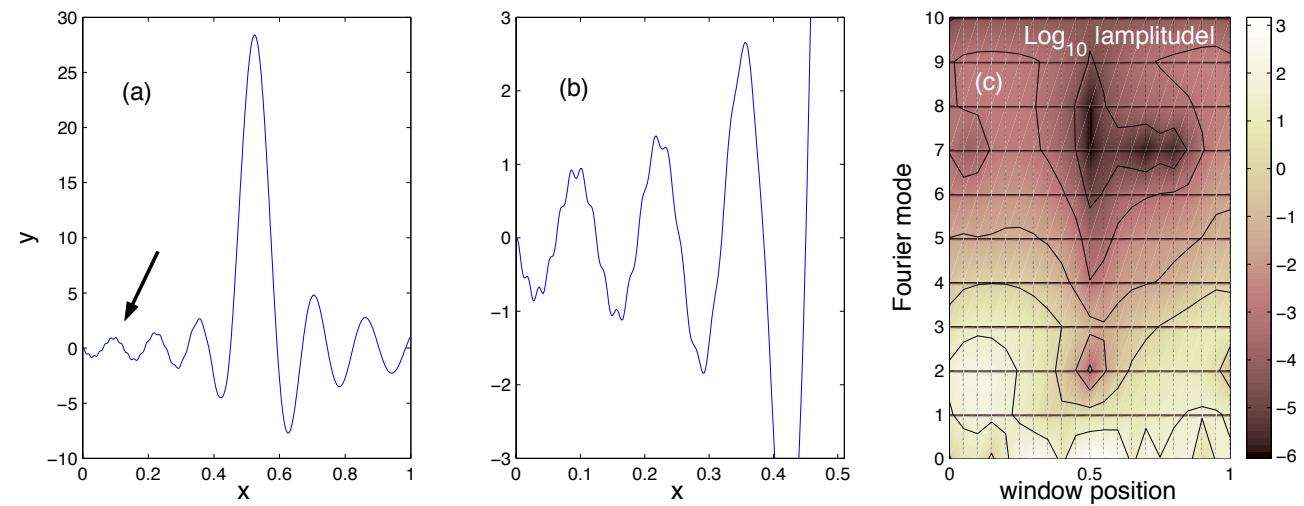

FIGURE 2. Solution of the fourth order equation obtained using $w / \Delta x=1.0, u \Delta x=0.9, N_{x}=21$ and $N_{F}=21$ : (a) solution, (b) blow-up of $x<0.5$ region, and (c) spectrogram (log of amplitude).

from $0.13-0.16$ across. Figure 2 shows the solution (a) with the short wavelength contribution from the slow wave clearly noticeable in (b). Picture (c) shows the mode structure in phase space, which depends on the choice of $u$ and $w$ parameters.

\section{CONCLUSIONS}

Good accuracy was achieved with the Gabor element method (GEM) when $u \Delta x<1$ and $w / \Delta x \sim 0.4-1$. A small Gaussian width $w$ yields a sparser matrix system but requires more Fourier modes. A larger $w / \Delta x \sim 1$ can be more efficient but yields a residual error that cannot be suppressed by increasing the resolution in phase space.

When optimally chosen, $u$ and $w$ yield an error that is insensitive to high order derivatives of the solution and so confers to GEM the capability to extract small and large features equally well. For problems with an oscillatory solution, GEM typically outperforms the finite element method error by several orders of magnitudes.

\section{ACKNOWLEDGMENTS}

Work supported by US DOE contract DE-AC02-76CH03073.

\section{REFERENCES}

1. Swanson, D. G., Theory of Mode Conversion and Tunneling in Inhomogeneous Plasmas, John Wiley \& Sons, Inc., 1998.

2. Smithe, D. N., Phillips, C. K., Hosea, J. C., Majeski, R. P., and Wilson, J. R., "Investigation of RF Absorption by Fast Ions and High Temperature Plasmas using the METS95 Wave Analysis Tool," in 12th Topical Conference on RF Power in Plasmas, Savannah, American Institute of Physics, New York, 1997, p. 367.

3. Daubechie, I., Ten Lectures on Wavelets, Society for Industrial and apllied Mathematics, 1992, chap. 3, pp. 53-63. 


\section{External Distribution}

Plasma Research Laboratory, Australian National University, Australia

Professor I.R. Jones, Flinders University, Australia

Professor João Canalle, Instituto de Fisica DEQ/IF - UERJ, Brazil

Mr. Gerson O. Ludwig, Instituto Nacional de Pesquisas, Brazil

Dr. P.H. Sakanaka, Instituto Fisica, Brazil

The Librarian, Culham Laboratory, England

Mrs. S.A. Hutchinson, JET Library, England

Professor M.N. Bussac, Ecole Polytechnique, France

Librarian, Max-Planck-Institut für Plasmaphysik, Germany

Jolan Moldvai, Reports Library, MTA KFKI-ATKI, Hungary

Dr. P. Kaw, Institute for Plasma Research, India

Ms. P.J. Pathak, Librarian, Insitute for Plasma Research, India

Ms. Clelia De Palo, Associazione EURATOM-ENEA, Italy

Dr. G. Grosso, Instituto di Fisica del Plasma, Italy

Librarian, Naka Fusion Research Establishment, JAERI, Japan

Library, Plasma Physics Laboratory, Kyoto University, Japan

Research Information Center, National Institute for Fusion Science, Japan

Dr. O. Mitarai, Kyushu Tokai University, Japan

Dr. Jiangang Li, Institute of Plasma Physics, Chinese Academy of Sciences, People's Republic of China

Professor Yuping Huo, School of Physical Science and Technology, People's Republic of China

Library, Academia Sinica, Institute of Plasma Physics, People's Republic of China

Librarian, Institute of Physics, Chinese Academy of Sciences, People's Republic of China

Dr. S. Mirnov, TRINITI, Troitsk, Russian Federation, Russia

Dr. V.S. Strelkov, Kurchatov Institute, Russian Federation, Russia

Professor Peter Lukac, Katedra Fyziky Plazmy MFF UK, Mlynska dolina F-2, Komenskeho Univerzita, SK-842 15 Bratislava, Slovakia

Dr. G.S. Lee, Korea Basic Science Institute, South Korea

Institute for Plasma Research, University of Maryland, USA

Librarian, Fusion Energy Division, Oak Ridge National Laboratory, USA

Librarian, Institute of Fusion Studies, University of Texas, USA

Librarian, Magnetic Fusion Program, Lawrence Livermore National Laboratory, USA

Library, General Atomics, USA

Plasma Physics Group, Fusion Energy Research Program, University of California at San Diego, USA

Plasma Physics Library, Columbia University, USA

Alkesh Punjabi, Center for Fusion Research and Training, Hampton University, USA

Dr. W.M. Stacey, Fusion Research Center, Georgia Institute of Technology, USA

Dr. John Willis, U.S. Department of Energy, Office of Fusion Energy Sciences, USA

Mr. Paul H. Wright, Indianapolis, Indiana, USA 
The Princeton Plasma Physics Laboratory is operated by Princeton University under contract with the U.S. Department of Energy.

\author{
Information Services \\ Princeton Plasma Physics Laboratory \\ P.O. Box 451 \\ Princeton, NJ 08543
}

Phone: 609-243-2750

Fax: 609-243-2751

e-mail: pppl_info@pppl.gov

Internet Address: http://www.pppl.gov 